\title{
ENGAGING WITH ACADEMIC INTEGRITY: A FOCUS ON THE TEACHER
}

\author{
Elaine Huber ${ }^{1}$, Oliver Coady ${ }^{1}$ \\ ${ }^{1}$ University of Technology Sydney (AUSTRALIA)
}

\begin{abstract}
Research into academic integrity has been approached from a range of perspectives. In many cases a student-centered approach is taken towards investigating academic literacies and the best ways in which to approach plagiarism, whether it be through lack of understanding or purposeful. Few studies focus on the teachers and this study will contribute to the body of knowledge in this regard by asking "How are staff being supported to redirect their understanding of academic integrity based on penalties and punishment towards a more supportive and sustainable approach?"
\end{abstract}

A first step could be to guide teachers to the location of relevant policies and procedures then to raise their awareness of their practicalities. From there, to develop understanding of how good assessment design and pedagogy can provide students with the opportunity to excel in their studies. This paper describes the design, development and implementation of a professional learning online module for staff at one Australian university. The online module enables staff to engage in critical discourse about academic integrity issues in an authentic context and through a community of practice.

\section{INTRODUCTION}

Academic Integrity (Al) is defined as "a commitment to... five fundamental values: honesty, trust, fairness, respect, and responsibility" [1]. Although this helps define Al, it does little to define and frame academic dishonesty. One such definition has been described by Gallant and Drinan [2] in that a breach of $\mathrm{Al}$ is behaviour that is incongruent with the five fundamental values. Throughout the literature, concepts such as collusion, plagiarism, and cheating all constitute the practice of academic dishonesty [3], [4], [5]. Communicating the illegitimate practice of these terms should, by all governing rights, prevent cases of academic dishonesty from occurring, however, communicating Al to all stakeholders is not as lucid as one might expect [6].

There is a growing body of research that describes ways in which to educate students on this topic [7], [5], as well as students' perceptions of Academic Integrity [3], [8]. There are numerous reasons why the topic of Academic Integrity (AI) is becoming more prevalent in the higher education sector including the rise in globalisation, internationalisation of the curriculum, and the prevalence of the Internet. Approaches to dealing with breaches of Al are also reported [9]. Academic dishonesty can give rise to ineffective student learning, undermine good scholarship, effect program efficacy and damage the reputation of individuals and the institution [10].

Organisations such as the Australian Government's Office for Learning and Teaching (OLT) fund a number of teaching and development projects through grant schemes. In the year of this study four of these projects (and $\$ 857,000$ in funding) were dedicated to research on $\mathrm{Al}$, indicating the importance of this topic to the governing body (OLT). The projects had input from fourteen Australian universities and covered topics on breaches of $\mathrm{Al}$ in non-text based assessments; culture and practice; policy and support frameworks; and resources and scholarship.

Academic Integrity issues have long played a part in the cultural discourse of Higher Education [9], [11]. Two distinct topics arise when considering Al, theft of Intellectual Property (IP) via plagiarism and cheating [12], [8], [13]; and the culture in higher education institutions of 'us vs them', [7], [3]. Although both discourses are distinctly different, they intertwine to help build the foundations of learning and teaching particularly around assessment. One issue presented by these discourses, as with many key industries outside of education, is the pervasive impact of the internet [14]. The steady rise of academic dishonesty in the USA can be paralleled with the growth of Internet ubiquity [15]. This rise is not limited to the United States. Cases of academic dishonesty are also on the rise in the UK in parallel with the growth of widespread Internet access [16]. Given the current developments of high speed Internet in Australia, Al warrants serious attention in both government policy and university practice. This is 
evidenced as outlined earlier by the investment by the OLT in research to identify strategies for implementing $\mathrm{Al}$ in higher education institutions.

According to several studies [7], [17], [18], students who practice academic dishonesty do so for a plethora of reasons, including: to help each other; they do not think they will be caught; the risk is worth the reward; fear and a pressure to perform; and social network influence. Each reason offers areas for exploration in policy development and research, however, this paper focuses on the student belief that they will not get caught, and social network influences, as research shows that these specific mindsets can be positively altered as a result of institutional activity without broaching ethical behavior [6]. Research reveals students who believe they will not get caught believe so for a variety of reasons, citing that academic staff will not identify cases of academic dishonesty, or worse, do nothing about their discoveries [19]; social norms within peer groups [7]; and the relationships between faculty staff and students [7], [14], [18]. These reasons identify two voices; the student and the teacher, where the student pushes the boundaries of Al within their social networks and academic practice, and the teacher lets them. This is exacerbated and exemplified by the terminologies used in institutional Al policies which typically place students in the role of 'breacher' and staff in the role of 'policer' [20].

Social networks are influential. Peers have immense influential prowess in encouraging one another to set, adhere or break social norms of a community [21]. This is discussed in great depth by Hutton, who states, 'Cliques-strongly connected, directly linked, dense subgroups of similar people-tend to develop as the size of the network increases, and are positively related to the probability of unethical behavior' [7 p. 173]. Since then, the rise of the digital native and new learner [22], [23] and advanced online social network sites, has brought on new and dynamic ways of peer influence [14]. The proliferation of social network activity, as a result of web 2.0 technologies, has brought about a massive surge in online community development and peer influence [23]. This kind of activity and influence is exacerbated with growth and ubiquity of mobile technologies. This creates the grounds for ultraconnected widespread social networks, built on social research where sharing information builds individual networks without mandated attribution [24]. The ease of communication in such ultraconnected networks takes control away from the teacher, and gives it to key members of an online participatory community [24]. The key players invest enough personal contribution to warrant the ability to set the social norms by which the participating community must abide [25]. Without extensive knowledge and understanding of $\mathrm{Al}$, there is no reason for these community leaders to set it as a socially practiced norm in student-run academic networks. Therefore, it is up to academics to establish a presence in any student-run network to provide a leadership role in Al. However, to achieve this, there needs to be a streamlined professional development initiative to empower academics in such a role.

Some academic staff tolerate academic dishonesty through fear of repercussions, guilt, emotional stress, lack of understanding of policy, and a lack of time to follow through with institutional procedures [19], and there is limited research to indicate that this has changed. Each of these reasons identifies a lack of action stemming from a highly cultivated cultural discourse brought about by the new approaches to education and academia. To some, higher education is seen to be transitioning from a knowledge based industry to service based one, thus there is a greater emphasis to consider students as customers who need to be kept happy while they pay for the service they consume [26]. This viewpoint encompasses a rhetoric of justifiable academic contention from the student body "we pay, you deliver". If staff fail to deliver the bare minimum of a pass, it is considered a black mark on their record, regardless if the student fails to meet the set standard. Empowered with this knowledge, students continue to push the boundaries of Al via collusion and plagiarism.

It is no wonder that a 'fear-of-repercussions' culture has arisen from such a service model approach. Education is being bought not learned [26]. This cultural discourse translates to a perpetual cycle where students act with academic dishonesty as a result of staff not committing to discipline breeches of $\mathrm{Al}$ [27], thus presenting the idea that academic integrity is not valued within the classroom [6]. Paired with this cycle is the notion of students believing that the risk is worth the reward, therefore, it should come as no surprise that academic dishonesty is on the rise. How can this 'us vs. them' culture be changed? This can be achieved through strengthening staff resolve in following institutional procedures, and providing opportunities for policy transparency between all stakeholders [7]. Use of honor codes for students (predominantly seen in the U.S.A.) are one way of developing a strong sense of community and interconnectedness [10].

Much research in the field has been dedicated to the means of communicating policy to students [7], [13], [9]. However, there is little, if any, literature surrounding the issue of educating staff on relevant policies in attempts to create a unified front against academic dishonesty. Al policy is preferred to be left out of the teacher/student relationship when cases of academic dishonesty are identified [21]. 
However, it is nonetheless an important policy to be aware of if we wish to ensure $\mathrm{Al}$ in higher education. The idea of charging administrators with the responsibility to endorse and support academic staff who identify cases of academic dishonesty is supported by Keith-Spiegel et al. [19]. Conversely, the idea of professional development of staff in Al policy is supported by Boehm, Justice \& Weeks [14]; however, little literature exists detailing the delivery and development of such staff training.

Developing staff knowledge and understanding of AI policy is one way of alleviating some of the stresses felt by academic staff when dealing with academic dishonesty [7], [14]. Furthermore, building staff capacity and support is a way of countering the students' perceptions that they will not get caught [6]. It may be beyond institutional capacity to stop students from helping one another without breaching their privacy. However, it is within higher educational institutions power to subvert the accepted norm of justifiable academic dishonesty. This can be achieved by developing and strengthening relationships between staff and students.

\section{BACKGROUND}

The Australian university described in this paper has an academic honesty policy that is available for staff to access via their central policy website. There is also a corresponding academic honesty procedure and accompanying academic dishonesty schedule of penalties that are to be followed by staff if a breach of academic honesty occurs from a student in their course. These policies and procedures were developed as a result of a review of the separate faculty practices. Each faculty (and in some cases each department within a faculty) had its own distinctively different procedures, causing confusion to students, particularly those who study across more than one faculty, department or school. Bringing the university together under one policy and framework was the first step towards combating the rise in academic dishonesty as concluded in the study by Bretag et al. in that

an exemplar policy needs to provide an upfront, consistent message, reiterated throughout the entire policy, which indicates a systemic and sustained commitment to the values of academic integrity and the practices that ensure it [28 p. 4].

As has been shown from the literature, staff development is crucial in developing a frontline against academic dishonesty. The central learning and teaching unit at the case university were tasked by the Academic Senate with providing supporting resources for staff on the topic of academic integrity and brought together a number of people including academics, educational developers, educational designers and academic language and learning specialists from across the institution into a working party to develop these. This kind of collaboration has been shown to be most valuable for learning and professional development purposes in higher education [29].

Based on the experiences of the members of the working party and the literature, considerable thought was given to the brief of staff development in the area of Al. A self-paced online module that raises awareness of the academic honesty policy and procedures through an action-oriented approach to learning, was deemed by the working party to be an effective starting point. This paper describes the design, development and implementation of this online module for staff at the case university.

\section{DESIGN PHASE}

There are various approaches to the design of professional development resources for educators. Studies identify constructivist learning, situated learning, collaboration, collegial networking, and access and support among others as conducive to teacher learning [30], [31], [32]. Then there is the 'mode':

Design methodologies need to be robust and general enough to cope with face-to-face, online and blended contexts, with synchronous and asynchronous interactions, as well as situations where teachers' time, skills or attention are limited - and even with situations in which there is no teacher' [33, p.2].

Similarly there are tried and tested approaches to the development of professional learning programs. These also include the above-mentioned modes of delivery that any educational course can use. In situations where technology can play an incremental role particularly on collective professional reflections, blended delivery is an effective method [34]. There have been recent successes in this mode for example a tutor induction program designed and developed at the case university won acclaim in the form of the Vice Chancellor's award for programs that enhance student learning [35], [36]. Other examples of blended learning are described in the literature detailing definitions, why to blend, how to blend and when not to blend. 
In parallel with blended delivery, online (only) delivery has been gaining ground in the higher education sector with the recent explosion onto the scene of Massive Open Online Courses (MOOCs). Higher Education Providers such as Open University, UK offer fully online degree programs and most Institutions now offer a range of courses and programs, which can be completed fully online. This appeals to the 21 st Century student who is typically balancing paid employment and in many cases carer responsibilities, with their studies [37]. A meta-analysis of over one thousand empirical studies of online learning from 1996 to 2008 found on average, students in online learning conditions performed modestly better than those receiving face-to-face instruction [38].

Lecturers report having less time to undertake all the tasks necessary to be successful in their careers and so professional development activities may have low priority, as they are seen as disaggregated from their main job [39]. With academic staff the intended audience for the Al resources described in this paper, it was decided to create a scaffolded learning path through the resource by designing it in an online environment using the university learning management system (LMS), Moodle.

Kandlbinder [40] conducted an examination of the use of online technology in professional development in thirty-one universities in Australia and the UK, and found that it was situated in a transmission model of communication and learning, mainly in an effort to save costs. Care was taken in the design phase for this online module to avoid such an approach to learning and instead to adopt an action-oriented design framework. Tools are available in Moodle to guide the learner through content (Lesson Tool) and test their understanding of that content (Quiz Tool). There are also tools available for encouraging self reflection (Blog Tool) and discussion (Forum Tool).

Communities of practice [41] long known for their ability to foster learning are also growing in stature in the online environment. In this medium, they provide opportunities for anytime anyplace learning, sharing and networking and allow for participation from disparate parts of the world. Such communities pave the way for professional learning for which "practice is an effective teacher and the community of practice the ideal learning environment' [42, p. 127]. The literature indicates that educational programs which involve communities of practice (CoPs), reflective practice and action learning, are most effective [43]. The design of the online module on Al borrowed principles from CoPs but was not wholly based on CoPs because in CoPs the participants can negotiate meaning. With Al, there are certain 'rules' and guiding principles which cannot be negotiated. The incorporation of assessment elements through quizzes and matching exercises allowed for elements of situated learning [44] to be included in the design.

The working party began with the aim for this online module, which was: To enhance awareness by academics (at the case university) of policy and good practice around Academic Integrity. The learning outcomes for the module were then developed and refined in an iterative process. The final set were:

1. Define/explain the meaning of academic honesty.

2. Locate and name relevant (case university) policy documents and resources

3. Describe how your unit addresses academic honesty

4. Identify appropriate steps to manage a suspected breach of the academic integrity (Al) policy.

5. Differentiate between the different types of plagiarism and academic integrity scenarios

Once these had been reviewed by stakeholders at the university, a constructive alignment [45] process was carried out by the working party developing a series of learning activities and assessment tasks to enable the learners to build their knowledge on each of the five topics and their associated learning outcomes. Each topic incorporated the 'lesson' module from Moodle which allows a scaffolding of content interspersed with checking points. These checks include quizzes of various types, reflection questions and group discussions. The two main types of activities and resources designed for use in this online module were a video and the discussion forum.

\subsection{Educational media}

The creation of a video that captures both staff and students' thoughts on academic integrity was deemed by the working party as instrumental to set the scene for the online module since 'Faculty prefer to learn about changes and innovation from people they know and to which they have immediate access $[46$, p. 6]. However, careful consideration should be put on any design that incorporates the potential of such technology in professional development, so that the learner does not simply become a passive recipient of knowledge. In other words, pedagogy must lead technology.

Four staff members from both academic and support areas, and four students from across campus were interviewed and their responses to the question: What do you understand by academic honesty? were 
recorded on film. The designers wished to use the term academic integrity as it is the term used predominantly in the literature, and in $41 \%$ of Australian Universities [28], however it was decided to use the term most familiar to the university community and the name of the policy (academic honesty). Making such a video had a secondary benefit of being transportable to other communication channels, and could also be used in an accompanying set of open resources on the central learning and teaching unit's public website.

To begin the online module, learners view the four-and-a-half-minute video and are asked to define their own understanding of academic integrity via an online discussion forum. The forum is set up in such a way that you cannot read others' definitions unless you have posted your own first. This allows for personal reflection followed by comment and discourse. This is an example of how and where elements of a CoP have been designed into the module. The definition of $\mathrm{Al}$ is not hard and fast and is open to interpretation. By creating a CoP, participants have the opportunity to develop their understanding through interaction with their peers.

\subsection{Online Discussion Forums}

Building community in the online space has been proven to be an effective means of fostering engagement with the content as well as higher order learning outcomes [30]. Text-based asynchronous discussion boards or forums offer the technology for learners to participate and achieve these goals. With the prevalence of social media, most learners no longer need support in using these tools, making the technology seamless and the learning prominent.

The academic integrity online module makes use of discussion forums throughout each of the five topics to provide opportunities for participants to tease out their thoughts and compare their experiences with those of their colleagues. One example of the use of a discussion forum is in the topic on breaches of academic honesty policy. In this topic, the learners are given a number of cases and asked questions (using a Quiz Tool) to test their understanding of the policy and how it may (or may not) be applied to each scenario. The discussion forum provides the opportunity for participants to critically discuss the scenarios and offer their agreement (or disagreement) with the given answers to the quiz questions, based on their own experience and understanding. It also offers them an they can share their own examples.

The working party reviewed the development of the online module at their regular monthly meetings. At the final stage of development, the outstanding items of concern (described below) were allocated, one to each member of the group, for peer review.

\section{REVIEW PHASE}

The design of the module was piloted with a group of eight academic staff. One area of slight concern was the amount of time required to complete the module. The working party discussed whether there was too much material to get through in the allocated one hour and deemed that this would depend on the participant's prior knowledge of Al. One suggestion to overcome this problem was to create a starting quiz similar to a needs analysis that directs participants to the topic(s) they need to focus on. This could be implemented by using a bank of questions, which are randomly selected. An alternative suggestion was to provide an example for discussion, which would act as a prompt to participants to continue on to the related topic in full. A third possibility, and the one that was subsequently implemented due to its pedagogical importance, was to add the learning outcomes at the beginning of the module linked to the corresponding topic. This made the curriculum alignment more explicit and transparent whilst giving participants the opportunity to self direct their learning to their specific needs.

The video was the next item reviewed. It was felt that a more detailed introduction was required, similar to a disclaimer. This could act as a stimulus to encourage the realisation that there are multiple perspectives and that the video is intended to be a conversation starter. From the participant's feedback, the working party questioned whether the activity following on from the video, of writing your own definition, was too difficult. Another option considered was to provide a number of alternative definitions and have participants vote on the 'best' one. Module participants could follow this up by adding a reflective comment on why they think it is the best. This activity could be repeated at the end of the module to investigate whether perspectives have changed through engaging with the module's content and activities.

The fourth topic in the online module, Preventing Breaches of Al, was discussed in depth by the working party. The importance of 'designing out' opportunities for plagiarism was well received by the pilot group. 
However, the content required for a topic on good assessment design could take up a whole module in itself and it was therefore decided to keep the topic simple and recommend it as an area for further development, perhaps in a second phase to the project.

This feedback along with reflections from the online module's facilitator were used to make final alterations to the activities as well as to correct any technical issues.

\section{IMPLEMENTATION PHASE}

The online module is currently open to staff all year round, through asynchronous self-enrolment. In other words, the module can be accessed at a time that is suitable to each individual rather than a predetermined start time such as the beginning of a semester when staff tend to be the busiest. This has the advantage of flexibility but lacks the advantages linked to belonging to a cohort. Studies have shown that belonging to a cohort can help professionals develop their identity and discover how their work influences and is impacted by others [47].

New staff receive instructions on how to access the module and a recommendation to do so, in their induction package when they begin working at the case university. This means that participants can access the module in their own time and work through the self-paced resources and activities. Alternatively, staff can access the module through two other means. First is a professional learning program called the Tutor Induction Program (TIP) [36]. Three of the four faculties at the case university pay their tutors and all casual staff to complete TIP. The academic integrity online module is one of the components that makes up this program and this financial incentive possibly explains the high numbers of enrolments. The third avenue for accessing the academic integrity online module is through another professional learning program on Blended Learning. This program requires participants to complete the academic integrity online module as part of a blended learning approach to teaching. In the first 15 months of running this module, it was completed by one hundred and fifty staff members.

\section{REFLECTIONS}

The course coordinator has adopted a developmental approach [48] to review, reflect on and evaluate the online module. At the end of each offering of the module, reflections from the facilitator are reviewed along with feedback from participants.

The facilitator of the online module plays an active role in drawing out the responses and finer details of participant activity. This is achieved by responding to participants' contributions and encouraging more critical thought by asking open-ended questions aimed to engage cognitive processes at the higher order end of Bloom's taxonomy (analyse, evaluate, create). In addition, the facilitator also provides links to resources as a means of offering other viewpoints of the category. Observations of participants' knowledge and understanding of Al varied from unsure to sound expressions of key concepts. Although most discussion topics were mutually agreed upon by participants, some questions revealed discrepancies between staff opinions of Al.

Responses from the discussion forums suggest that although staff know of plagiarism and how to identify it, they sometimes find it difficult to recognise other forms of academic dishonesty. For example, there is an ongoing debate across all participants' responses regarding the position taken with regards to collusion. Although the module clearly defines collusion, some staff find it difficult to differentiate the term from components of collaboration. This illustrates the ambiguous nature of Al. It also supports the literature regarding students' perceptions of not getting caught [3], as it is understandable that some students may acknowledge their collaboration as collusion [49], but also consider several factors that make the reward worth the risk. For example, students may realise the discrepancies between collusion and collaboration can be blurred, and thus hard to recognise [49]. Furthermore, students may also have insight into the required effort, both administrative and emotional, from staff to actually proceed with reporting offences. Although these causes are purely speculative, it is clear from turning the lens away from students and onto staff, that Al needs greater internal support strategies such as this professional learning module along with clear guidelines for determining what constitutes a breach of Al.

Some confusion was generated within the online Al module as a result of language. Some staff were unsure as to whether the module was referring to the integrity of staff or students due to the word 'academic' in Al. Responses generated from this confusion ranged from participants answering questions based on individual perceptions of their own practice of academic honesty, to participants getting rather disgruntled, believing the online module was being rather audacious in questioning their 
academic integrity as a professional. This confusion was unexpected from the module convenor, and warrants their continued input as a facilitator. Such responses from participants also acted as anecdotal feedback insofar as providing information for development of future iterations.

\section{FUTURE DIRECTIONS}

The academic integrity module focuses on informing staff, and increasing transparency, of policies and procedures. However, in order to truly create a united practice, the university recognised the need for a corresponding student-focused module. The working party continued to meet once the staff online module was implemented and moved into the delivery phase but this time with a new focus, to produce a corresponding online module for students. The chair of the 'new' working party changed from the learning and teaching centre (who primarily support staff) to the learning skills group (who primarily support students).

The student Academic Integrity module has been developed to inform students of the university policy and procedure surrounding $\mathrm{Al}$, and aims to define terms and concepts surrounding academic dishonesty. Topics covered include What is Academic Integrity? What can I do to avoid plagiarism? and What are my responsibilities and rights as a university student? The student module is self-contained and is accessed from the university's learning management system. The module is set up with open registration so any student can access it at anytime.

The student and staff modules share information and principles, but offer alternative perspectives to create an even playing field for all stakeholders. This will allow for alignment of delivery with literature surrounding Al policy transparency [6]. The student module looks at Al through the lens of students, and explains the responsibilities they must take when committing to academia. The staff module views Al through the academic lens, and expresses the responsibilities, as well as support, staff have in upholding academic integrity. It is hoped the student Al module will help share the responsibility of Al across the university campus and this is one area for future research direction.

There are a few studies that have investigated the benefits of developing staff and student resources that complement each other [50], [51]. Future developments could investigate the benefits of a combined online module for both staff and students. Little research has been done in this area and such a module could pave the way for a shared understanding of Al across the institution.

\section{CONCLUSION}

This paper describes the design, development and implementation of an online module for staff designed to raise awareness of Academic Integrity policies and procedures at one Australian university. Whilst the online module is still in its infancy, progress is being made in terms of achieving these goals. The online module enables staff to engage in critical discourse about academic integrity issues in an authentic context and through a community of practice. The next stage in the developmental cycle for this module is to further the work on designing assessment to remove the opportunity for breaches of Al to occur. In line with this, an online student module on Al has been designed, developed and trialled.

\section{REFERENCES}

[1] International Center for Academic Integrity. (n.d.). Fundamental Values Project [Online]. Available: http://www.academicintegrity.org/icai/resources-2.php

[2] T. B. Gallant and P. Drinan, "Toward a model of academic integrity institutionalization: Informing practice in postsecondary education," Canadian Journal of Higher Education, vol. 38, no. 2, pp. 24-43, 2008.

[3] J. M. Gullifer and G. A. Tyson, "Who has read the policy on plagiarism? Unpacking students' understanding of plagiarism," Studies in Higher Education, pp. 1-17, Aug. 2013. doi:10.1080/03075079.2013.777412

[4] B. Oldham, "Impact of an Online Library Tutorial on Student Understanding of Academic Integrity," Catholic Library World, vol. 82, no. 1, pp. 27-31, 2011. 
[5] C. Mainka, S. Raeburn, and S. Earl, "A UK institution's university-wide approach to plagiarism: First results and recommendations," International Journal for Educational Integrity, vol. 2, no. 1, pp. 13-25, 2003.

[6] D. L. McCabe, K. D. Butterfield, and L. K. Trevino, "Faculty and Academic Integrity: The Influences of Current Honor Codes and Past Honor Code Experiences," Research in Higher Education, vol. 44, no. 3, pp. 367-385, 2003.

[7] P. A. Hutton, "Understanding Student Cheating and What Educators can do About it," College Teaching, vol. 54, no. 1, pp. 171-176, 2006. doi:10.3200/CTCH.54.1

[8] L. G. Power, "University Students' Perceptions of Plagiarism," The Journal of Higher Education, vol. 80, no. 6, pp. 643-662, 2009. doi:10.1353/jhe.0.0073

[9] G. T. Crisp, "Staff attitudes to dealing with plagiarism issues: Perspectives from one Australian university," International Journal for Educational Integrity, vol. 3, no. 1, pp. 3-15, 2007.

[10] S. Saddiqui, "On My Honour!: An Investigation into the Feasibility of Academic Honour Codes in the Australian University Context," PhD dissertation proposal, School of Education, Macquarie University, Sydney, NSW, Australia, 2013 [PowerPoint slides]. Available:

http://www.slideshare.net/SoniaSaddiqui/phd-research-proposal-presentation-sonia-saddiqui28-nov-2013

[11] M. C. Lester, and M. George, "A comparison of traditional and internet cheaters," Journal of College Student Development, Vol. 43, no. 6, pp. 906-911, 2002.

[12] K. C. Petress, "Academic dishonesty: A plague on our profession," Education, vol.123, no. 3 , pp. 624-627, 2003.

[13] D. L. McCabe, K. D. Butterfield, and L. K. Trevino, "Academic Dishonesty in Graduate Business Programs: Prevalence, Causes, and Proposed Action," Academy of Management Learning \& Education, vol. 5, no. 3, pp. 294-305, Sept. 2006. doi:10.5465/AMLE.2006.22697018

[14] P. J. Boehm, M. Justice, and S. Weeks, "Promoting academic integrity in higher education," Community College Enterprise, vol. 15, no. 1, pp. 45-61, 2006.

[15] M. C. Lester, and M. George, "A comparison of traditional and internet cheaters," Journal of College Student Development, vol. 43, no. 6, pp. 906-911, 2002.

[16] A. Dordoy, "Cheating and plagiarism: staff and student perceptions at Northumbria," Proceedings of the Northumbria Conference, 2002.

[17] L. E. Nilsson, A. Eklöf, and T. Ottosson, "I'm entitled to make mistakes and get corrected': students' self positioning in inquiries into academic conduct", Critical Discourse Studies, vol. 6, no. 2, pp. 127-152, 2009.

[18] S. A. Stearns, "The Student-Instructor Relationship's Effect on Academic Integrity," Ethics \& Behavior, vol. 11, no. 3, pp. 275-285, 2001.

[19] P. Keith-Spiegel, B. G. Tabachnick, B. E. Whitley Jr, and J. Washburn, "Why professors ignore cheating: Opinions of a national sample of psychology instructors," Ethics \& Behavior, vol. 8, no. 3, pp. 215-227, 1998.

[20] W. Sutherland-Smith, "Retribution, deterrence and reform: the dilemmas of plagiarism management in universities," Journal of Higher Education Policy and Management, vol. 32, no. 1, pp. 5-16, Jan. 2010. doi:10.1080/13600800903440519

[21] D. L. McCabe and L. K. Trevino, "Academic dishonesty: Honor codes and other contextual influences," The Journal of Higher Education, vol. 64, no. 5, pp. 522-538, 1993.

[22] N. Selwyn, "The digital native - myth and reality," Aslib Proceedings, vol. 61, no. 4, pp. 364379, Jul. 2009. doi: 10.1108/00012530910973776

[23] R. Doiron and M. Asselin, "Exploring a new learning landscape in tertiary education," New Library World, vol. 112, no. 5/6, pp. 222-235, May 2011. doi: 10.1108/03074801111136266

[24] K. Gray, C. Thompson, J. Sheard, R. Clerehan, and M. Hamilton, "Students as Web 2.0 authors: Implications for assessment design and conduct," Australasian Journal of Educational Technology, vol. 26, no. 1, 2010. 
[25] D. W. McMillan and D. M. Chavis, "Sense of community: A definition and theory," Journal of community psychology, vol. 14, no. 1, pp. 6-23, 1986.

[26] R. K. Yeo and M. J. Marquardt, "Through a different lens: bridging the expectation-perception (quality) divide in higher education," Asia Pacific Journal of Education, vol. 31, no. 4, pp. 379405, Dec. 2011. doi:10.1080/02188791.2011.621589

[27] M. Roig and C. Ballew, "Attitudes toward cheating of self and others by college students and professors," The Psychological Record, vol. 44, no. 1, p. 3, 1994.

[28] T. Bretag et al., "Core elements of exemplary academic integrity policy in Australian higher education," International Journal for Educational Integrity, vol. 7, no. 2, 2011.

[29] T. Ferman, "Academic professional development practice: What lecturers find valuable," International Journal for Academic Development, vol. 7, no. 2, pp. 146-158, Nov. 2002. doi: 10.1080/1360144032000071305

[30] D. R. Garrison and N. D. Vaughan, Blended Learning in Higher Education: Framework, Principles, and Guidelines. San Fransisco: Jossey-Bass, 2008.

[31] D. H. Jonassen and L. Rohrer-Murphy, "Activity theory as a framework for designing constructivist learning environments," Educational Technology Research and Development, vol. 47, no. 1, pp. 61-79, Mar. 1999. doi:10.1007/BF02299477

[32] J. A. Taylor, "Managing staff development for online education: A situated learning model," Journal of Higher Education Policy and Management, vol. 25, no. 1, pp. 75-87, 2003. doi: $10.1080 / 13600800305742$

[33] Y. Dimitriadis and P. Goodyear, "Forward-oriented design for learning: illustrating the approach," Research in Learning Technology, vol. 21, no. 1, p. 20290, Apr. 2013. doi:10.3402/rlt.v21i0.20290

[34] E. F. Holton III, M. L. Coco, J. L. Lowe, and J. V. Dutsch, "Blended delivery strategies for competency-based training," Advances in Developing Human Resources, vol. 8, no. 2, pp. 210 228, 2006. doi: $10.1177 / 1523422305286153$

[35] B. Handal and E. Huber, "Development of the New Academic: The Case for Blended Delivery," in Research and Development in Higher Education: Reshaping Higher Education, Gold Coast, Australia, 2011, vol. 34, pp. 150-160.

[36] E. Huber, S. Hoadley, and L. Wood, "Teaching Induction Program: Framework, Design and Delivery," Asian Social Science, vol. 7, no. 11, p. 13, 2011.

[37] P. Ramsden, "The future of higher education teaching and the student experience," Report for the UK Government Department for Buisness, Innovation \& Skills, 2008.

[38] B. Means, Y. Toyama, R. Murphy, M. Bakia, and K. Jones, "Evaluation of evidence-based practices in online learning: A meta-analysis and review of online learning studies.," US Department of Education, 2009.

[39] H. Carter, "Utilising the educational resource development process to scaffold the professional development of university teachers," in Proceedings of EDMEDIA 2005: World Conference on Educational Multimedia, Hypermedia \& Telecommunications, Montreal, Canada, 2005, pp. 2644-5.

[40] P. Kandlbinder, "Peeking under the covers: on-line academic staff development in Australia and the United Kingdom," International Journal for Academic Development, vol. 8, no. 1-2, pp. 135143, 2003.

[41] E. Wenger, Communities of practice: Learning, meaning, and identity. Cambridge university press, 1998

[42] J. S. Brown and P. Duguid, The social life of information. Harvard Business Press, 2000.

[43] R. P. Warhurst, "'We Really Felt Part of Something': Participatory learning among peers within a university teaching-development community of practice," International Journal for Academic Development, vol. 11, no. 2, pp. 111-122, Nov. 2006. doi:10.1080/13601440600924462 
[44] J. Lave and E. Wenger, Situated learning: Legitimate peripheral participation. Cambridge university press, 1991.

[45] J. Biggs and C. Tang, Teaching for Quality Learning at University, 3rd ed. Berkshire, England: Open University Press, 2007.

[46] D. M. Jacobsen, "Adoption Patterns of Faculty who Integrate Computer Technology for Teaching and Learning in higher Education.," presented at the ED MEDIA/ED TELECOM 98 World Conference on Educational Multimedia and Hypermedia \& World Conference on Educational Telecommunications, Freiburg, Germany, 1998.

[47] B. J. Johnson, M. Goulian, J. Donovan, and A. G. Pang, "Comparison to Celebration: Developing a Theory of Group Membership," Journal of Student Affairs, vol. 21, p. 18, 2012.

[48] M. Patton, "Developmental evaluation," American Journal of Evaluation, vol. 15, no. 3, pp. 311319, 1994.

[49] A. Sutton and D. Taylor, "Confusion about collusion: working together and academic integrity," Assessment \& Evaluation in Higher Education, vol. 36, no. 7, pp. 831-841, Dec. 2011. doi:10.1080/02602938.2010.488797

[50] M. Botterill, G. Allan, and S. Brooks, "Building community: Introducing ePortfolios in university education," in Hello! Where are you in the landscape of educational technology, Melbourne, 2008.

[51] M. A. McNeill, L. S. Arthur, Y. A. Breyer, E. Huber, and A. J. Parker, "Theory into practice: Designing Moodle training for change management," Asian Social Science, vol. 8, no. 14, p. 58, 2012. 